\title{
Haemoglobin and prognosis in childhood acute lymphoblastic leukaemia
}

\author{
IAN M HANN, JOHN H SCARFFE, MICHAEL K PALMER, DAVID I K EVANS, AND \\ PATRICIA H MORRIS JONES
}

Department of Haematology and Department of Oncology, Royal Manchester Children's Hospital, and Department of Medical Statistics and Department of Medical Oncology, Christie Hospital, Manchester

SUMMARY Two hundred and nine children presenting consecutively with acute lymphoblastic leukaemia to a regional paediatric oncology unit were investigated to determine the prognostic significance of various factors at diagnosis. There was a strong positive correlation between the pretreatment haemoglobin level and the percentage of bone marrow blast cells in $\mathbf{S}$ phase of the cell cycle as assessed by flow cytometry. Patients with T- and B-cell leukaemia had significantly higher haemoglobin levels than non-B non-T patients. In patients with total white cell counts $<20 \times 10^{9} / 1$, aged $<13$ years, and no mediastinal mass, there was no association of haemoglobin with length of first remission. However, among those with white blood counts $>20 \pm 10^{9} / 1$ there was a strong positive trend towards shorter remission with higher haemoglobin levels. Children with high white blood counts at diagnosis and low haemoglobin levels may have a better prognosis than predicted by the white blood count alone.

There have been few attempts to relate the haemoglobin $(\mathrm{Hb})$ level at diagnosis of childhood acute lymphoblastic leukaemia (ALL) to the eventual outcome of the disease. In cases in which this factor has been studied it has not generally been in groups comprising children alone, ${ }^{12}$ or such study has produced inconsistent results. ${ }^{3-6}$ We thus decided to look at a consecutive unselected group of children to determine the relationship between haemoglobin and prognosis of the disease.

Patients and methods. The Royal Manchester Children's Hospital, Paediatric Oncology Unit serves a large area of the North West of England and takes an unselected population. ${ }^{7}$ Two hundred and nine patients who presented consecutively during a 6-year period to October 1977 were studied. ALL was diagnosed using the criteria of Hayhoe et al. ${ }^{8}$ Blasts always constituted more than $30 \%$ of marrow cells.

Thirty-two prognostic factors present at diagnosis were investigated and the findings with some of them have been reported elsewhere. ${ }^{9-14}$ Each factor was analysed for its effect on duration of first remission because the prognosis is known to be poor after relapse. ${ }^{15}$ Remission curves were calculated by the life table method and compared by the log rank test. ${ }^{16}$ These tests were (1) a test for heterogeneity between the groups, and (2) a test for trend.

The first test determines whether there is a significant difference between the groups, irrespective of the order in which they were numbered; the second test takes into account the order of the groups (from low to high $\mathrm{Hb}$ for instance).

The curve for each subgroup of patients was summarised by calculating the relative relapse rate. This is defined as the ratio of the number of relapses in the subgroup during the period of follow-up related to the number expected, on the assumption that prognosis was the same in all subgroups. Thus, a relapse rate greater than unity would indicate a fairly poor prognosis and a relapse rate less than unity a fairly good one.

A Hb level was obtained on all patients before transfusion and before starting treatment using a Coulter haemoglobinometer. ${ }^{17}$ All patients were treated subsequently with a standard induction protocol for ALL together with cranial irradiation, intrathecal methotrexate, and 4-drug maintenance, generally according to the current UK Medical Research Council protocol. Maintenance therapy was continued for 3 years after the disease had been diagnosed. 


\section{Results}

Twenty-three per cent of patients had $\mathrm{Hb}$ levels $<5 \mathrm{~g} / \mathrm{dl} ; 40 \%$ were between 5 and $7.4 \mathrm{~g} / \mathrm{dl} ; 30 \%$ were between 7.5 and $10.9 \mathrm{~g} / \mathrm{dl} ; 7 \%$ were $>11 \mathrm{~g} / \mathrm{dl}$ (Table). There was a strong positive correlation between $\mathrm{Hb}$ level and percentage of blasts in $\mathrm{S}$ phase of cell cycle $(r=0.36 ; P<0.02 ; n=42)$.

The mean $\mathrm{Hb}$ level was $6.0 \mathrm{~g} / \mathrm{dl}$ in 68 children with non-B, non-T cell leukaemia, and $7.9 \mathrm{~g} / \mathrm{dl}$ in 11 patients with $\mathrm{T}$ - or B-cell leukaemia. This difference was statistically significant $(P<0 \cdot 01)$.

Table Haemoglobin level compared with length of first remission in childhood acute lymphoblastic leukaemia

\begin{tabular}{|c|c|c|c|c|}
\hline Groups & $H b(g / d l)$ & $\begin{array}{l}\text { No of } \\
\text { patients }\end{array}$ & $\begin{array}{l}\text { Relative } \\
\text { relapse rate }\end{array}$ & $P$ for trend \\
\hline Total & $\begin{array}{l}<5 \\
5-7 \cdot 4 \\
7 \cdot 5-10 \cdot 9 \\
>11\end{array}$ & $\begin{array}{l}49 \\
83 \\
63 \\
14\end{array}$ & $\left.\begin{array}{l}0.82 \\
0.91 \\
1.20 \\
1.45\end{array}\right\}$ & 0.052 \\
\hline Good prognosis & $\begin{array}{l}<5 \\
5-7 \cdot 4 \\
7 \cdot 5-10 \cdot 9 \\
>11\end{array}$ & $\begin{array}{r}29 \\
59 \\
41 \\
6\end{array}$ & $\left.\begin{array}{l}0.89 \\
0.92 \\
1.30 \\
0.52\end{array}\right\}$ & $0 \cdot 7$ \\
\hline Poor prognosis & $\begin{array}{l}<5 \\
5-7 \cdot 4 \\
7 \cdot 5-10 \cdot 9 \\
>11\end{array}$ & $\begin{array}{r}20 \\
24 \\
22 \\
8\end{array}$ & $\left.\begin{array}{l}0.61 \\
1.11 \\
1.08 \\
2.88\end{array}\right\}$ & $0.002^{*}$ \\
\hline
\end{tabular}

Patients in whom prognosis is good are not black, have WBC $<20 \times 109 / 1$, are aged $<13$ years, and have no mediastinal mass. Patients in whom prognosis is poor have at least one of the above features.

* Statistically significant value.

A strong statistically significant trend towards shorter remission time with higher haemoglobin level is present in patients for whom prognosis is poor but not in 'good risk' children.

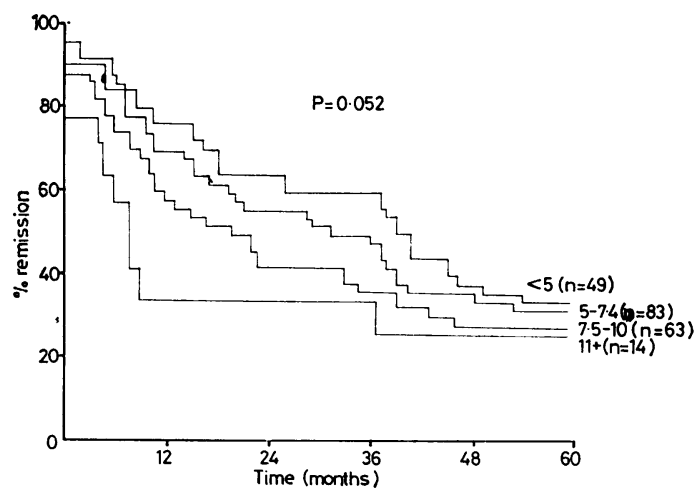

Fig. 1 Haemoglobin level compared with length of first remission for patients with acute lymphoblastic leukaemia. Trend towards poorer prognosis with increasing haemoglobin levels just fails to reach statistical significance $(P=0.052)$
When all patients were analysed together there was a trend towards longer first remission times with lower haemoglobin which just failed to reach statistical significance $(P=0.052$; Table; Fig. 1). When patients with traditional good risk features were analysed separately (white blood count (WBC) $<20 \times 10^{9} / 1$, no mediastinal mass, aged $<13$ years, and not black) the $\mathrm{Hb}$ level had no influence on prognosis (P=0.7) (Fig. 2). However, in patients with poor risk features a higher $\mathrm{Hb}$ level was strongly correlated with shorter remission times $(P=0.002)$ (Fig. 3). The median length of first

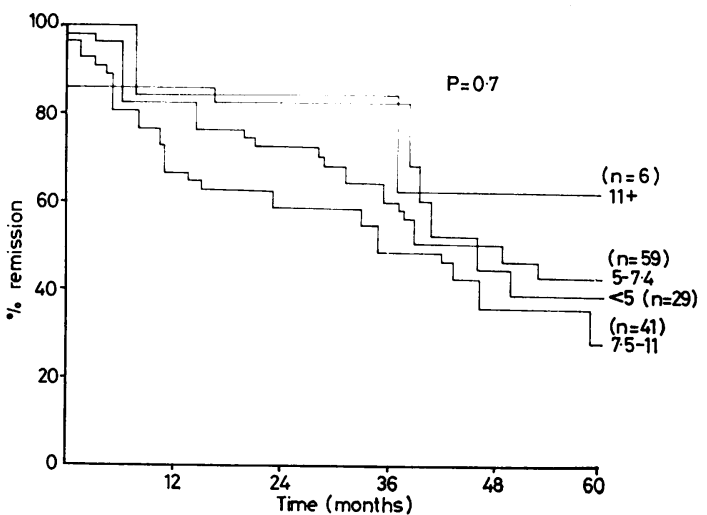

Fig. 2 Haemoglobin level compared with length of first remission for patients with good prognosis. No statistically significant effect $(P=0 \cdot 7)$.

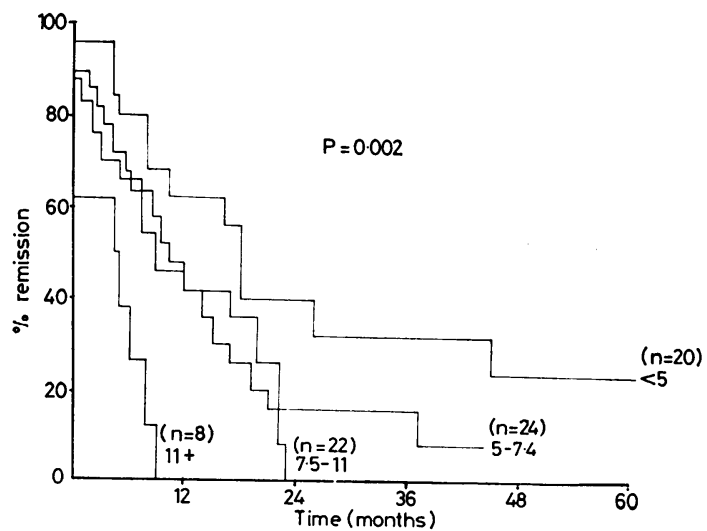

Fig. 3 Haemoglobin level for patients with poor prognosis. There is a statistically significant trend to shorter duration of first remission with higher haemoglobin $(P=0.002)$. The median lengths of first remission for haemoglobin levels of $<5,5-11$, and $>11 \mathrm{~g} /$ dl are 18,9 , and 4 months respectively. 
remission for poor risk patients with haemoglobin levels of $<5 \mathrm{~g} / \mathrm{dl}, 5-10.9 \mathrm{~g} / \mathrm{dl}$, and $>11 \mathrm{~g} / \mathrm{dl}$ were 18,9 , and 4 months respectively.

\section{Discussion}

The percentage of patients with low $\mathrm{Hb}(<5 \mathrm{~g} / \mathrm{dl})$, intermediate levels $(5-10 \mathrm{~g} / \mathrm{dl})$, and high $(>10 \mathrm{~g} / \mathrm{dl})$ are similar to other series-that is 23,62 , and $15 \%$ respectively. ${ }^{56}$

A small series of 6 children and 61 adults treated between 1957 and 1964 described by Gunz and Burns in $1965^{1}$ was the first report relating $\mathrm{Hb}$ levels to prognosis. Their finding was that lower levels conferred a worse outlook for the disease. The study of Zippin et al. ${ }^{2}$ showed an improvement in median survival time with increasing $\mathrm{Hb}$ up to a level of $9 \mathrm{~g} / \mathrm{dl}$ above which the prognosis was worse. A similar result was shown by George $e t$ al..$^{5}$ but this trend was thought not to be statistically significant. Simone $^{4}$ failed to demonstrate any significance for this factor, although there was a trend towards worse survival over $8 \mathrm{~g} / \mathrm{dl}$. However, Lonsdale et al. ${ }^{3}$ found a poor prognosis in patients with high $\mathrm{Hb}$ levels which was confirmed in the recent report of Miller et al. ${ }^{6}$ in which an association of high $\mathrm{Hb}$ level with high WBC negates some of its independent influence on prognosis in a multivariate analysis. Our results provide an explanation for the inability of some studies to demonstrate a statistically significant effect on prognosis. This effect is confined to patients with other poor risk factors and analysis of a complete group of children will blur its significance.

The reason why a high $\mathrm{Hb}$ level confers a poor outlook can be found in its association with the pretreatment proliferative activity of bone marrow blast cells and, to a lesser extent, with T-cell type of disease. We showed previously ${ }^{14}$ that a higher percentage of blasts in $\mathrm{S}$ phase of cell cycle carries a poor prognosis, and that T-cell disease is associated with a higher percentage of cells in S phase. It would thus seem reasonable to assume that the group of patients with high WBC and high $\mathrm{Hb}$ levels have a rapidly multiplying malignancy, and they present before the $\mathrm{Hb}$ has time to fall.

About one-quarter of patients with traditional poor risk factors have $\mathrm{Hb}$ levels $<5 \mathrm{~g} / \mathrm{dl}$ and they may be expected to do appreciably better than poor risk patients with higher $\mathrm{Hb}$ levels. This group may achieve a median length of first remission of 18 months with a $25 \% 5$-year disease-free survival. In our series all patients with a WBC of $>20 \times 10^{9} / 1$ and $\mathrm{Hb}$ of $>7 \cdot 5 \mathrm{~g} / \mathrm{dl}$ had relapsed by 22 months and all had died by 3 years. This group of about $15 \%$ overall clearly responds poorly to current treatment and would be suitable for consideration of novel approaches to treatment.

\section{References}

1 Gunz F W, Burns E W. Prognosis in acute leukaemia of adults. NZ Med J 1955: 64: 555-61.

2 Zippin C, Cutler S J, Lum D. Time trends in survival in acute lymphocytic leukemia. J Natl Cancer Inst 1975; 54: 581-6.

3 Lonsdale D, Gehan E A, Fernbach D J, Sullivan M P, Lane D M, Ragab A $\mathbf{H}$. Interrupted vs continuous maintenance therapy in childhood acute leukemia. Cancer 1975; 36: 341-52.

4 Simone J V. Prognostic factors in childhood acute lymphocytic leukaemia. Adv Biosci 1975; 14: 27-42.

5 George S L, Fernbach D J, Vietti T, et al. Factors influencing survival in pediatric acute leukemia. The SWCCSG experience, 1958-1970. Cancer 1973; 32: 1542-53.

6 Miller D R, Leikin S, Albo V, Vitale L, Hittle R, Sather H, Hammond D. New prognostic factors in childhood acute lymphoblastic leukemia (abstract). Am Soc Clin Oncol 1979; C 244.

7 Draper G, Birch J, Bithell J, et al. Childhood cancer in Britain 1953-1975. London: HMSO, 1981. In press.

8 Hayhoe F G J, Quaglino D, Doll R. The cytology and cytochemistry of acute leukaemia. Special Report Series, 304. London: Medical Research Council, 1964.

9 Hann I M, Evans D I K, Marsden H B, Morris Jones P H, Palmer M K. Bone marrow fibrosis in acute lymphoblastic leukaemia of childhood. J Clin Pathol 1978; 31 : 313-5.

10 Hann I M, Evans D I K, Palmer M K, Morris Jones P H, Haworth $\mathrm{C}$. The prognostic significance of morphological features in childhood acute lymphoblastic leukaemia. J Clin Lab Haematol 1979; 1 : 215-26.

11 Hann I M, Gupta S, Palmer M K, Morris Jones P H. The prognostic significance of radiological and symptomatic bone involvement in childhood acute lymphoblastic leukemia. Med Pediatr Oncol 1979; 6: 51-5.

12 Hann I M, Morris Jones P H, Evans D I K, Addison G M, Palmer M K, Scarffe J H. Low IgG or IgA-a further indicator of a poor prognosis in childhood acute lymphoblastic leukaemia. Br J Cancer 1980; 41 : 317-9.

13 Palmer M K, Hann I M, Morris Jones P H, Evans D I K. A score at diagnosis for predicting length of remission in childhood acute lymphoblastic leukaemia. $\mathrm{Br} J$ Cancer 1980; 42: 841-9.

14 Scarffe J H, Hann I M, Evans D I K, et al. The relationship between the pretreatment-proliferative activity of bone marrow blast cells measured by flow cytometry and prognosis of ALL of childhood. $\mathrm{Br} J$ Cancer $1980 ; 41: 764-72$

15 Cornbleet $\mathrm{M} \mathrm{A}$, Chessells $\mathrm{J}$ M. Bone marrow relapse in acute lymphoblastic leukaemia in childhood. $\mathrm{Br}$ Med J 1978; ii: $104-6$.

16 Peto R, Pike M C, Armitage P, et al. Design and analysis of randomised clinical trials requiring prolonged observation of each patient. II. Analysis and examples. $B r J$ Cancer 1977; 35: 1-39.

17 Dacie J V, Lewis S M. Practical haematology, fifth edition. Edinburgh: Churchill Livingstone, 1975: 21-67.

Correspondence to Dr I M Hann, Department of Haematology, Royal Free Hospital, Pond Street, London NW3 2QG.

Received 6 June 1980 